\title{
MASTER
}

\section{Materials Technology for Accelerator Production of Fissile Isotopes}

\author{
J. A. Horak
}




\section{DISCLAIMER}

This report was prepared as an account of work sponsored by an agency of the United States Government. Neither the United States Government nor any agency Thereof, nor any of their employees, makes any warranty, express or implied, or assumes any legal liability or responsibility for the accuracy, completeness, or usefulness of any information, apparatus, product, or process disclosed, or represents that its use would not infringe privately owned rights. Reference herein to any specific commercial product, process, or service by trade name, trademark, manufacturer, or otherwise does not necessarily constitute or imply its endorsement, recommendation, or favoring by the United States Government or any agency thereof. The views and opinions of authors expressed herein do not necessarily state or reflect those of the United States Government or any agency thereof. 


\section{DISCLAIMER}

Portions of this document may be illegible in electronic image products. Images are produced from the best available original document. 


\section{Printed in the United States of America. Available from National Technical Information Service \\ U.S. Department of Commerce \\ 5285 Port Royal Road, Springfield, Virginia 22161 \\ Price: Printed Copy $\$ 4.50$; Microfiche $\$ 3.00$}

This report was prepared as an account of work sponsored by an agency of the United States Government. Neither the United States Government nor any agency thereof, nor any of their employees, contractors, subcontractors, or their employees, makes any warranty, express or implied, nor assumes any legal liability or responsibility for any third party's use or the results of such use of any intormation, apparatus, product or process disclosed in this report, nor represents that its use by such third party would not infringe privately owned rights. 
ORNL/TM-6156

Distribution

Category UC- 25

Contract No. W-7405-eng-26

METALS AND CERAMICS DIVISION

MATERIALS TECHNOLOGY FOR ACCELERATOR PRODUCTION OF FISSILE ISOTOPES

J. A. Horak

Date Published - February 1978

To be published in the proceedings of the

International Conference on Alternative

Energy Sources, University of Miami, December 5-7, 1977

NOTICE This document contains information of a preliminary nature. It is suhjert in revision or correction and therefore does not represent a final report.

OAK RIDGE NATIONAL LABORATORY

Oak Ridge, Tennessee 37830

operated by

UNION CARBIDE CORPORATION

for the

DEPARTMENT OF ENERGY 
THIS PAGE

\section{WAS INTENTIONALLY \\ LEFT BLANK}




\section{CONTENTS}

ABSTRACT . . . . . . . . . . . . . . . . . . . . . . 1

INTRODUCTION . . . . . . . . . . . . . . . . . . . . 1

A. TARGET . . . . . . . . . . . . . . . . . . 3

1. Liquid Metal . . . . . . . . . . . . . . . 3

2. Solid Metal . . . . . . . . . . . . . . . 4

3. Particles of Heavy Metal Compounds . . . . . . . . . . 6

4. Reactor Fuel Elements . . . . . . . . . . . . 8

B. TARGET CONTAINER . . . . . . . . . . . . . . . . . . . . . . 9

C. FERTILE BlANKET . . . . . . . . . . . . . . . . . . . . 12

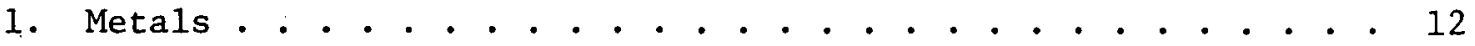

2. Ceramics . . . . . . . . . . . . . . . . . . 14

3. Reactor Fue1 Elements . . . . . . . . . . . . . . . 15

D. BLANKET CONTAINER . . . . . . . . . . . . . . . . . . . . 15

E. NEUTRON MULTIPLIER . . . . . . . . . . . . . . . . 16

F. WINDOW BETWEEN ACCELERATOR AND TARGET . . . . . . . . . . . . . 17

REFERENCES . . . . . . . . . . . . . . . . . . . . . . 18 
J. A. Horak

Metals and Ceramics Division

Oak Ridge National Laboratory

Oak Ridge, Tennessee U.S.A.

\section{ABSTRACT}

The materials used for the accelerator production of fissile isotopes must enable the facility to achieve maximum fuel production at a minimum cost. Neutron production in the target would be maximized by use of thorium cooled with $\mathrm{Pb}-56 \% \mathrm{Bi}$ or with sodium. The thorium should be ion-plated with approximately 1 mil of nickel or stainless steel for retention of fission products. The target container will have to be replaced at frequent intervals because of the copious quantities of neutronically produced helium and hydrogen in the container. Replacement would coincide with shutdown of the facility for the removal of the fissile material produced. If sodium is used to cool both the target and fertile blanket, a simple basket-type target container could be used. This would greatly reduce radiation effects in the target container. Type 316 stainless steel or V-20 wt \% Ti should perform satisfactorily as a target container. The fertile blanket should be ${ }^{23{ }^{3}} \mathrm{Th}$ or ${ }^{238} \mathrm{U}$ that is coated with approximately $1 \mathrm{mil}$ of nickel or stainless steel and cooled with sodium. The blanket contalner could be an austenitic stainless steel such as type 304 or 316 ; some ferritic alloys may also provide a satisfactory blanket container.

\section{INTRODUCTION}

Large numbers of neutrons can be produced when heavy elements are irradiated with a high current $(\geqslant 100 \mathrm{MA}$ ) of energetic protons ( $\sim 1$ GeV). [1,2] These neutrons could be used to produce fissile material for nuclear reactors. Surrounding the irradiation target with fertile ${ }^{232}$ Th or ${ }^{238} \mathrm{U}$ would enable fissile ${ }^{23{ }^{3}} \mathrm{U}$ and ${ }^{239} \mathrm{Pu}$ respectively to be produced during this process. The concepts that employ this method of producing fissile isotopes have been called Accelerator Breeders, $A B$, or Electronuclear Breeders, ENB. [3-6] For conciseness, the use of high energy accelerators for the production of fissile isotopes will be abbreviated $A B$.

The materials performance in an $A B$ must be optimized for reliable and economic fuel production to be achieved. This does not mean that

*Research sponsored by the Department of Energy under contract with Union Carbide Corporation. 
the materials used in the $A B$ have to last forever; however, it does mean that they must last for reasonably long times and during shutdown of the facility for the removal of fuel and insertion of new fertile material. If the materials that experience the high fluxes of high energy neutrons can be replaced at the same time the facility is shut down, the economics of the fuel production by the $A B$ would be enhanced greatly. The information presented herein is based on the following five criteria that are considered important to the operation of an $\mathrm{AB}$ fuel factory.

1. The materials technology should enable the achievement of maximum neutron production.

2. The blanket should have a maximum fertile atom density to promote maximum breeding.

3. The target-blanket region must be simply designed for tasy replacement of components and insertion of fertile material and removal of fuel in a short time.

4. Development work required to optimize materials performance for an $A B$ will be based on existing irradiation, elevated temperature, and strength and chemical compatibility information.

5. The $A B$ will be designed to provide maximum use of the resources of this planet.

For the purpose of this presentation, the following simple design concept is employed. The accelerator is approximately $1 \mathrm{~km}$ long and horizontally positioned with a $90^{\circ}$ bend at the end where the proton beam is magnetically deflected downward to the target, which is a right circular cylinder that is surrounded by a cylindrical fertile blanket. This configuration is the same as that used for fast breeder reactor blankets.

This design is used to keep the accelerator, target, and blanket as independent as possible, thus, enabling them to perform their separate functions in the other components of the facility. This modular construction will minimize plant downtime and will facilitate repair and/or maintainance of any one of the three components. I'he close coordination of materials selection with mechanical and/or structural design requires close, continuous cooperation between the materials and design engineers. The materials-design relationship must be optimized to produce maximum performance of the system.

An outline of the materials technology for this design will be presented. The following discussion and this outline will be based on the aforementioned five criteria and the information available. The research and development necessary to optimize the performance of the $A B$ will be recommended. The information will be presented in the following order:

A. Target

1. liquid metal

2. solid metal 
3. particles of heavy metal compounds

4. reactor fuel elements

B. Target Container

C. Fertile Blanket

1. metals

2. ceramics

3. reactor fuel elements

D. Blanket Container

E. Neutron Multiplier

F. Window Between Accelerator and Target

\section{A. TARGET}

The technology of the materials used for the target must provide the following:

1. maximum neutron production,

2. heat removal rates adequate to maintain the desired temperature in the target,

3. chemical compatibility with the target wall,

4. thermal stresses sufficiently below the yield or fatigue stresses for solids, and

5. resistance-to-radiation effects that can be accommodated by a combination of materials properties and design parameters.

\section{Liquid Metal}

The primary candidates for the target are liquids of high atomic number such as lead and bismuth or preferably the eutectic alloy $\mathrm{Pb}-56$ wt $\% \mathrm{Bi}$, which has the desirable low melting point of $125^{\circ} \mathrm{C}$. Advantages of a liquid target such as lead-bismuth, or possibly lithium, are that there are neither thermal stresses generated in the target nor radiation damage effects produced in the target and that heat removal can be readily accomplished. If the target volume that the protons strike is full of lead, the maximum volume of material for neutron production is achieved, which is one of the goals for the $A B$. The lead-bismuth eutectic alloy is easy to maintain as a liquid because of its low $125^{\circ} \mathrm{C}$ melting point. The use of a liquid target eliminates the need for a window between the accelerator and the target. The vapors from the liquid can be trapped at the accelerator exit by using cold traps and baffles at the point where the accelerator enters the target region.

Both lead-bismuth and lithium exhibit chemical compatibility with a type 316 stainless steel to approximately $500^{\circ} \mathrm{C}$. [7] This compatibility is especially true if reactive species, such as magnesium or zirconium, are added to lead-bismuth to preferentially react with impurity species (including proton-induced transmutation) [5] that may be present in the material. [8] Therefore, the compatibility of the liquid target with the target wall of type 316 
stainless steel will not be a limiting factor in the life of the target material or wall material, especially at the temperatures anticipated for a lead-bismuth target (i.e., $<250$ to $300^{\circ} \mathrm{C}$ ). Good compatibility also exists for lead alloys with ferritic steels. Use of low-alloy ferritic steel would be more economical than the use of a stainless steel for the target wall.

An additional material that appears to have excellent mechanical and radiation effects properties for the wall of the target and would contain the liquid lead-bismuth is $\mathrm{V}-20 \mathrm{wt} \% \mathrm{Ti}$; this will be discussed later in Section $B$.

Research and Development Required

1. Compätibility studies of $\mathrm{V}-20$ wt $\% \mathrm{Ti}$ with lead-bismuth and/or lithium at temperatures to approximately $300^{\circ} \mathrm{C}$ are required. Currently, thcre are no data on $\mathrm{V}-20$ wt \% Ti with either liqu1d. Proof testing of both type 316 stainless steel ferritic alloys and $\mathrm{V}-20 \mathrm{wt} \% \mathrm{~T} 1$ under anticipated $\mathrm{AB}$ energy deposition and flow rates should be pcrformed.

2. The efficiencies of various reactive elements ( $\mathrm{Zr}, \mathrm{Ti}$, and $\mathrm{Mg}$ ) in the lead-bismuth and/or cold traps for removing impurities and/or transmutations from the lead-bismuth must be determined.

3. Some design studies and proof testing for optimizing the flow rate and geometry of the liquid in the target for maximum neutron production must be conductcd.

\section{Solid Metal}

The two metals that have a high potential for use as a target are uranium and thorium. The use of uranium or thorium would result in increased neutron production over that possible in a lead-bismuth target. Protons of $1 \mathrm{GeV}$ produce approximatedy 20 neutrons per proton in a lead or lead-bismuth target and approximately 40 neutrons per proton in a thorium or uranium target. [1] The five materials technology requirements presented earlier in this section are better satisfied hy thori.um.

The thorium would be in the geometry of cylindrical plates or plate segments such as quadrants stacked on top of one another with rnnlant space provided between plates. This is the form of the fuel for fast burst reactors, where energy deposition rates are very high and peak dynamic stresses are large.[9] Since the increase in beam amperage in the $A B$ from startup to full power would be in programmed increments, the energy deposition rates in the $A B$ would be increased much more slowly than those that occur in a fast burst reactor, and the resulting thermal stresses would appear to be acceptable. Since the plates would be stacked to a considerably greater height than the mean free path for the GeV protons in thorium, none of the protons would be, wasted with this target geometry. 
For maximum neutron production, lead-bismuth would be the most desirable coolant, but lithium or sodium would also be acceptable. If sodium is used as the coolant for the target and for the blanket, the target container could be greatly simplified. The target container could consist of a bottom grid having three or four strips of metal spaced 90 or $120^{\circ}$ apart and attached to an outer ring. To the outer ring could be attached three or four vertical rods to form a type of basket for inserting and removing the target plates and for keeping them in their desired location during irradiation.

This arrangement would provide maximum cooling of the target plates; more importantly, the basket concept greatly minimizes the radiation effects in the target container since only a very small volume of structural material would be exposed to the high flux of energetic neutrons.

If helium is used as a coolant, a window would be required between the target and the accelerator vacuum. This will be discussed later in Section F.

Bare thorium and thorium-uranium alloys exhibit excellent compatibility with sodium at temperatures of at least $500^{\circ} \mathrm{C}[10]$, but bare thorium would most probably not be used because of the production of $233 \mathrm{U}$ and subsequent fissions in the target plates. This would introduce fission products into the coolant, leading to contamination of components. Although this contamination may be acceptable because the target wall and blanket structural components will also be very radioactive, it is not necessary or desirable. The use of ion plating on fast burst reactor fuel plates is a very effective and proven method for retention of fission products. and minimizing the contamination of components. [11-13]

Uranium could be utilized as a target material, but it is much less desirable than thorium because of its poorer chemical, mechanical, and physical properties. [14-15]

For example, uranium has a high corrosion rate, orthorhombic crystal structure, a low-temperature phase transformation at $660^{\circ} \mathrm{C}$, and a lack of mechanical and dimensional stability under irradiation and/or thermal cycling. [14]

In addition, a ${ }^{238} \mathrm{U}$ target would produce ${ }^{239} \mathrm{Pu}$. One of the principal uses of the $A B$ would be to produce the initial ${ }^{23}{ }^{3} \mathrm{U}$ required for commercial use of the ${ }^{232} \mathrm{Th}-{ }^{233} \mathrm{U}$ fuel cycle, which has advantages over the ${ }^{238} \mathrm{U}-{ }^{239} \mathrm{Pu}$. [1.6].

The disadvantages of a solid target are:

1. Radiation damage will be produced in the solid by protons, neutrons, and fission fragments.

2. Large internal gas pressures may be generated by the protons that come to rest in the target and from the xenon and krypton fission products. 
3. The protons that are stopped in the thorium will probably form thorium hydride, $\mathrm{ThH}_{2}$ or $\mathrm{ThH}_{4}$. Both forms occupy a larger volume than thorium and produce large internal strains. This could be a source of crack initiation during heating and/or cooling, and the interface between the thorium and a thorium hydride is an excellent path for crack propagation.

4. The fission products in the target require that an effective barrier to their release be provided.

5. A coolant such as lead-bismuth or sodium is still required.

6. The target will have to be removed periodically, which may detract from the simplicity of the system.

However, ${ }^{23} \mathrm{U}$ would be produced in the thorium target, probably at a high rate. Ihe fact that the thorlum is also a useable component of the fuel is a large advantage which may more than offset the listed disadvantages. A thorium target would most probably have to be removed berause of $2{ }^{3}{ }^{3} \mathrm{Il}$ hili 1 dup ronsiderahly hefore $i$ t.s nperation was affected by radiation damage, gas pressure, or hydride formation. These phenomenon may not limit the target lifetime.

Research and Development Required

1. Design studies to optimize the geometry of the target components, maximize neutron production, minimize internal strains, and provide for simple insertion and removal are required.

2. The temperature of the target that provides the maximum target lifetime must be determined. Information on hydrogen diffusion and hydride formation needs to be evaluated.

3. The ion-plated material and thickness must be optimized in order to provide maximum fission product and ${ }^{233} \mathrm{U}$ retention in the target.

4. Potential coolants based on neutronics, chemical compatibility, and simplicity of design must be evaluated. For example, with a thorium target and a thorium blanket, a wall between the target and the blanket may not be required, and the same coolant could be used for both.

The research and development required for a uranium target would be considerably greater than that for a thorium target, and the performance of a uranium target would be inferior to that of a thorium target due to the less desirable chemical, crystaliographic, méchanical, and phyeical properties of urantum.

\section{Particles of Heavy Metal Compounds}

The use of $\mathrm{UO}_{2}$ or $\mathrm{ThO}_{2}$ spheres (or other forms) as the target is possible but extremely difficult. The designs using $\mathrm{UO}_{2}$ or $\mathrm{ThO}_{2}$ spheres at approximately $50 \%$ packing fraction significantly reduce the neutron production, since only 15 to $16 \%$ of the target volume would be available for producing neutrons. [6] Thermal stresses in the oxides would be large because of their low thermal conductivity, which decreases further with increasing temperature. The particles would have to be 
coated with a barrier material for fission product retention, and differential thermal expansion of the particle may crack the barrier layer (or layers), thus contaminating the system with fission products. This problem would be especially severe in designs that use high pressure, approximately 1400 psi, and high-velocity helium coolant. It would be extremely difficult to keep fission products from migrating everywhere in the target region and in all the associated piping.

In HTGR applications, the power densities in oxide particles are from 0.02 to $0.01 \mathrm{~W}$ per particle.[17] At these power densities, the integrity of the oxide particles is retained for maximum irradiation temperatures to approximately $1200^{\circ} \mathrm{C}$. Operation at power levels up to 1 watt per particle in an HTGR is possible under certain conditions. [18] For power levels greater than 1 watt per particle, the particles usually fail by cracking.

In the commercial design 1160-MW(e) HTGR, the average power density per particle is 0.02 watt, with a maximum power density of 0.1 watt. [17] For the 300-MW proton beam to be deposited in the oxide particles to produce 0.1 watt per particle, $3 \times 10^{9}$ particles are required; these particles must be kept moving through the target area at all times. This does not appear to be feasible because of the large energy deposition in the particles or the uniform movement of a billion particles. Also, temperature gradients produced in particles that are in contact with each other will result in migration of the oxide kernel through the coating, the so-called amoeba effect.[18]

The protons from the accelerator will come to rest within the oxide particles producing hydrogen gas. At elevated temperatures, the. hydrogen will most probably diffuse out of the particles and not cause any undue stresses due to agglomeration of the hydrogen into bubbles. However, if the gas were to be trapped between the particle and its coatings, it would cause a large tensile strain in the coating and could result in a coating failure early in life of the particle.

The use of a particle-type target requires high-pressure helium coolant at a high velocity of helium at a pressure of approximately 1400 psi. Since the accelerator is under very high vacuum, this concept requires that a window be present at the end of the accelerator to separate the vacuum from the helium. Such a window is well beyond current technology.

Research and Development Required

The following determinations must be made:

1. the heat removal capabilities of $\mathrm{ThO}_{2}$ and/or $\mathrm{UO}_{2}$ spheres as a function of beam power, particle size, and particle flow rate;

2. the effects of radiation damage to the oxide kernel and to the protective coating;

3. the effects of hydrogen on the oxide kernel, the coating, and the coating-kernel interface; 
4. the ability of the particles to resist cracking due to mechanical stresses as they move through the target region; and

5. the neutron production as a function of particle packing density and beam power.

\section{Reactor Fuel Elements}

Some $A B$ concepts employ a typical pressurized water reactor (PWR), boiling water reactor (BWR), or gas-cooled fast reactor (GCFR) fuel element for the target. [4-6] From a materials technology consideration, these would appear to be the least promising target concept. The fuel pin in the water-cooled reactor fuel elements consists of a stack of 40 to $50 \mathrm{UO}_{2}$ pellets measuring approximately $3 / 8$ in. in diameter and approximately $3 / 8$ 1n. Iong which are clad 1 n Zircaloy-4 that is approximately 0.015 in. thick. For the GCFR design, the pellets are of similar dimensions but the $\mathrm{UO}_{2}$ contains approximately $20 \% \mathrm{PuO}_{2}$. The GCFR cladding is type 316 stainless steel, which is also approximately $0.015 \mathrm{in}$. thick. For the water-cooled reactors, helium fills the space between the fuel and the clad. The space is provided to accommodate fuel pellet swelling from the fission product gases xenon and krypton. For the GCFR, sodium fills the space between the fuel and clad to provide the higher heat transfer required in the GCFR compared with a light water reactor (LWR). For both these types of targets, the cladding would be severely embrittled by the hydrogen produced by protons coming to rest in the cladding. The $\mathrm{UO}_{2}$ or $\mathrm{ThO}_{2}$ would probably crumble from thermal stresses. When this occurs, small pieces of the $\mathrm{UO}_{2}$ or $\mathrm{ThO}_{2}$ become wedged between the fuel pellets and the cladding. During subsequent heating, these pieces exert a highly localized stress on the cladding. This stress produces strains in the cladding that may easily exceed the strain for yielding, or possibly even the strain for fracture. [19]. The Zircaloy and stainless steel would also be severely embrittled by the large concentrations of hydrogen and helium. The hydrogen and helium are produced by the high energy neutrons resulting from the $1-\mathrm{GeV}$ protons interacting with the $\mathrm{UO}_{2}$ or $\mathrm{ThO}_{2}$ in the target. This phenomenom is discussed further in Section $B$.

Furthermore, the fuel element arrangement does not provide high neutron production in the target. A considerable portion of the volume in such a target is occupied by cladding, helium or sodium in the space between the clad and the $\mathrm{UO}_{2}$ or $\mathrm{ThO}_{2}$, space between adjacent fuel pins in the fuel element, and by non-neutron-producing oxygen.

Such a target design would require frequent replacement, possibly as often as every day.[19] This would significantly decrease the plant availability factor, even for a design where the target elements could be replaced in an extremely short time by some ingenious method. They will be very radioactive and require special remote handling, as for any fuel element transfer. The remote handling will have to be precise because the cladding will most probably fracture at low levels of stress (e.g., where it has been bumped or dropped). 
$\underline{\text { Research and Development Required }}$

The following determination must be made:

1. the neutron production relative to that of a solid thorium target cooled with lead-bismuth and relative to that of lead-bismuth;

2. the effects of the hydrogen produced in the oxide and in the cladding;

3. the coolant requirements of this target design;

4. the lifetime of a fuel element exposed to 1-GeV protons at approxi.mately $300 \cdot \mathrm{mA}$ of beam current; and

5. the radiation damage (including helium) effects in the fuel, cladding, and support structure.

\section{B. TARGET CONTAINER}

The materials technology required for the target container is to ensure that it will withstand the thermal stresses that are produced in it, the mechanical stresses or pressure stresses that may be produced as a result of pressure of the liquid target, the helium coolant, and/or the differential pressurc between the target and blanket reglon, chemical compatibility, and radiation effects. In addition, the target wall should be easy to replace so that it can be done when the fuel is being removed and fertile material is being added in the blanket region.

All of the alloys will have a finite lifetime while serving as the target wall of the $A B$. Alloys that would appear to be able to perform adequately, in order of increasing price, are low-alloy ferritic steels, type 316 stainless steel, and $\mathrm{V}-20 \mathrm{wt} \% \mathrm{Ti}$. The thermal stresses and coolant stresses should be acceptable for these alloys, especially if the target wall is maintained at a temperature below approximately $400^{\circ} \mathrm{C}$. The chemical compatibility of all of the aforementioned target species is acceptable for type 316 stainless steel at tenperatures below $500^{\circ} \mathrm{C}$. Data are required for the compatibility of $\mathrm{V}-20 \mathrm{wt} \% \mathrm{Ti}$ with targets such as lead-bismuth or lithium and with impurity species such as $\mathrm{H}, \mathrm{O}$, and $\mathrm{N}$. Compatibility of the target wall with the target will not be the limiting factor for container lifetime.

The container wall, which will have dimensions on the order of 2 to $3 \mathrm{ft}$ in diameter, requires a technology that is more closely related to that of a fusion reactor rather than the technology for fission reactors. The most important property for the target wall is resistance to fracture so that the liquid target or the coolant of the solid target does not enter the blanket or vice versa. Swelling of the target wall is not the main criterion and will not limit the lifetime of the wall in the $A B$ because of its large diameter and design to be loose fitting for easy insertion and removal. Therefore, reasonable amounts of swelling would not interfere with this operation. The major effect produced by the neutrons on the target container will 
be the generation of very large amounts of helium and hydrogen by $(n, \alpha)$ reactions and $(n, p)$ reactions, respectively. Since the neutrons from the target striking the target container will have energies up to $200 \mathrm{MeV}$, consideration must be given to the increase in the helium and hydrogen production cross sections at neutron energies greater than $5 \mathrm{MeV}$. These cross sections are 10 and 100 times greater, respectively, than those at $1 \mathrm{MeV}$.

For a first approximation, we can use some of the information obtained in the fusion-reactor radiation effects program. In the $A B$, it has been stated that the neutron flux at the target wall is approximately $5 \times 10^{16} \mathrm{n} / \mathrm{cm}^{2} \mathrm{~s}$ with a $1 / E$ dependence from $1 \mathrm{KeV}$ to $200 \mathrm{MeV}$. [6]

For purposes of illustration, this can be compared with the neutron flux that exists in a Tokamak, or mignelli fusiun ledetor, MFR, which is $2.7 \times 10^{14} \mathrm{n} / \mathrm{cm}^{2} \mathrm{~s}(E>0.1 \mathrm{MeV})$ at $1 \mathrm{MW} / \mathrm{m}^{2}$. For a simple comparison, consider a flux at the AB target wall of $2.7 \times 10^{16} \mathrm{n} / \mathrm{cm}^{2}(E>0.1 \mathrm{MeV})$ which is 100 times greater than that in the Tokamak. If we assume for a first simple approximation that the dpa (displacement per atom), helium, and hydrogen cross sections are approximately constant over the neutron energy range of 5 to $200 \mathrm{MeV}$, then their production rates will be approximately 100 times greater than that in the first wall of a Tokamak. For type 316 stainless steel in a Tokamak operating at $1 \mathrm{MW} / \mathrm{m}^{2}$ and $100 \%$ duty factor, the hydrogen, helium, and $\mathrm{dpa}$ per month are 50 appm (atomic parts per million), 15 appm, and 1 respectively. For the target container of the $\mathrm{AB}$ at an $80 \%$ duty factor, these values exceed 3700 appm H, 1200 appm He, and 80 dpa per month. The dpa, helium, and hydrogen produced in the target wall during one month are equivalent to those produced in an MFR during approximately eight years of operation.

If the target wall temperature is kept below $400^{\circ} \mathrm{C}$, the helium atoms produced should not diffuse or cause severe embrittlement of type 316 stainless steel or $\mathrm{V}-20 \% \mathrm{Ti}$. The helium will affect void nucleation and growth which contribute to the swelling rate.[20-22] This however, can be tolerated in the target wall for several reasons: (1) the target wall is extremely large, (2) close ficting arrangements with adjacent components are not required; and (3) the target wall does not have the same structural requirements as those of the first wall of an MFR.

However, at temperatures even slightly above room temperature, hydrogen moves very rapidly. The movement of hydrogen could result in severe grain boundary embrittlement of the target wall if the hydrogen agglomerates into bubbles. If the hydrogen can permeate the wall and escape, it will not result in agglomeration of bubbles at the grain boundaries and or in severe embrittlement. If this occurs, the major effect of the hydrogen will be on the void nucleation and growth rates which contribute to swelling, but as mentioned previously, this can be tolerated. 
Type 316 stainless steel has been exposed to fluences as high as approximately $4 \times 10^{23} \mathrm{n} / \mathrm{cm}^{2}(E>0.1 \mathrm{MeV})$ in the Rhapsodie and Phenix LMFBRs. [23] There have been no catastrophic effects, and swelling has been on the order of 3 to $6 \%$, which is certainly very tolerable for this application. [23] However, the energy of the neutrons is low; therefore, the total amount of helium and hydrogen is.approximately $100 \mathrm{appm}$, resulting in no observed embrittlement at temperatures below $500^{\circ} \mathrm{C}$ for type 316 stainless steel. In recent experiments in the High Flux Isotope Reactor, HFIR, 20\% cold-worked (CW) type 316 stainless steel has been irradiated at temperatures from 575 to $605^{\circ} \mathrm{C}$ to approximately $60 \mathrm{dpa}$ and $4200 \mathrm{appm} \mathrm{H}$. Even with this much helium, this material exhibited greater than $0.5 \%$ elongation at a testing temperature of $575^{\circ} \mathrm{C} \cdot[24]$

More recent information has been obtained on type 316 stainless steel$20 \% \mathrm{CW}$ for irradiation and testing temperatures more relevant to the $\mathrm{AB}$. [25] The samples were irradiated at $380^{\circ} \mathrm{C}$ and tested at $350^{\circ} \mathrm{C}$. For these conditions, the tensile ductility remains above $2 \%$, which should be quite satisfactory for the $A B$. The helium concentration achieved corresponds to approximately 3 months in the $A B$ at a $90 \%$ duty factor. Hence, if the target container is of a simple design, it could be changed at 3-to 4-month intervals (or longer), concurrent with shutdown for removal of fuel and insertion of new fissile material. The ductility of this material at temperatures of interest for the target container of the $A B$ should be very satisfactory if the ductility behavior at the high helium contents is similar to that observed for the $20 \%$ cold-worked type 316 stainless steel irradiated in HFIR.

Recent information on the mechanical properties of $\mathrm{V}-20$ wt \% $\mathrm{Ti}$ irradiated in Experimental Breeder Reactor-II (EBR-II) is also available. The alloy was irradiated at fluences up to $6.1 \times 10^{22} \mathrm{n} / \mathrm{cm}^{2}(E>0.1 \mathrm{MeV})$ at temperatures between 400 and $900^{\circ} \mathrm{C}$ and then tensile-tested at approximately the irradiation temperature. The ductility values after this irradiation history were close to the unirradiated values in the range of 15 to $20 \%$ over the entire temperature range. [26] Ductility values for similar samples of stainless steel irradiated in this temperature range are approximately 1 to $2 \%$. In addition, no voids were observed by transmission electron microscopy, and there was no swelling of the alloy over the entire temperature-irradiation fluence history obtained. No other alloy has ever exhibited this type of performance. The potential of $\mathrm{V}-20 \% \mathrm{Ti}$ containing helium and hydrogen relevant to those for the $A B$ needs to be determined.

The lifetime of the target wall will most likely be limited by the concentration of the gases hydrogen and helium produced by the high energy neutrons which will contribute to the loss of ductility in the wall. Since this loss of ductility has a very marked temperature dependence, the lifetime of the wall certainly would be longer if the wall were to be operated at temperatures lower than those necessary to provide the thermodynamic efficiency required in a power-producing nuclear reactor. The wall lifetime will be limited by neither chemical compatibility nor by the swelling produced by the ordinary fission reactor energy neutrons. 
Research and Development Required

The following determinations must be made:

1. the effects of high levels of dpa, helium, and hydrogen on the ductility of low-alloy ferritic steels, type 316 stainless steel, or a member of that family, and of $\mathrm{V}-20 \mathrm{wt} \% \mathrm{Ti}$ at required temperatures of operation for the $A B$,

2. the effects of dpa, helium, and hydrogen on the swelling behavior of these two materials,

3. the effects of dpa, helium, and hydrogen on the fatigue and creepfatigue behavior of these alloys.

4. In addition, a simple target container, such as a right circular cylinder, a split cylinder, or a tapered cylinder that contains metallic o-rings at the top and bottom must be designed. These designs make possible easy removal and replacement of the target cuntainer in an $A B$.

\section{FERTILE BLANKET}

The technology of the materials used for the fertile blanket must provide the following:

1. maximum fertile atom density,

2. heat removal rates adequate to maintain the desired temperatures in the fertile materials,

3. chemical compatibility with clad and coolant,

4. minimum thermal stresses in the fertile material and the support structure, and

5. materials that enable simple fabrication and processing to be used.

\section{Metals}

Thorium is the most desirable fertile blanket material for the following reasons:

1. Thorium provides the maximum fertile atom density and the highest fissile atom production.

2. Thorium is isotropic and exhibits excellent resistance to irradiation damage even when it contains large concentrations of uranium. [27,28]

3. Thorium has a thermal conductivity more than ten times greater than that of the $\mathrm{UO}_{2}$ and $\mathrm{ThO}_{2}$ decrease with increasing temperature for temperatures of interest for the $A B$. [29] This enables a thorium blanket to be operated at temperatures much lower than those required for a $\mathrm{UO}_{2}$ or $\mathrm{ThO}_{2}$ blanket. This is very desirable for system reliability and component lifetime.

4. Thorium has a high melting point of $1755^{\circ} \mathrm{C}$. [15] Therefore, its properties are approximately isotropic, and it does not have any low-temperature phase transformations such as those that occur in anisotropic uranium. [14] 
5. Thorium has a low elastic modulus equal to one-half that of $\mathrm{ThO}_{2}$ and one-third that of uranium and of $\mathrm{UO}_{2}$. [29] The low elastic modulus, combined with high thermal conductivity, minimizes thermal stresses and allows higher power densities to be achieved in the blanket; if high power densities are not a criterion, it allows for the highest fissile atom production rates in the blanket. From a power-producing standpoint, thorium-uranium alloys have been operated under power reactor conditions at power ratings two to three times those that have currently been achieved for $\mathrm{UO}_{2}$ and $\mathrm{ThO}_{2}$. One disadvantage to the thorium-uranium system is that the heat capacity is equal to only one-half that of the two oxides, urania and thoria.

6. Of extreme importance is the fact that thorium-uranium alloys containing up to $20 \mathrm{wt} \% \mathrm{U}$ have exhibited the best irradition behavior of all fissile and fertile materials irradiated thus far. $[27,28]$

7. If it is permissible to operate the thorium with an ion-plated fission product retention barrier, it would tremendously simplify the fabrication and processing of the fuel bodies for converting fertile atoms to fissile atoms. A very large portion of the expense of a conventional fuel pin (i.e., fuel + heat transfer media + cladding) is due to the fuel element cladding. The cladding is very expensive to fabricate, and welded end closures must be provided. Most fuel pin failures occur due to defects in the tubing wall and/or end closure welds. Elimination of a cladding and $a$ heat transfer media between the fertile material and the clad, followed by the disassembly and the discarding of the fuel element cladding would greatly reduce the cost of the fissile material produced in the $A B$.

Thorium is considerably more abundant than uranium; in addition, the United States has very large deposits of thorium, and ${ }^{233} \mathrm{U}$ provides more neutrons per fission than does either ${ }^{235} \mathrm{U}$ or ${ }^{239} \mathrm{Pu}$. Therefore, the use of the ${ }^{232} \mathrm{Th}-{ }^{23} \mathrm{U}$ fuel cycle would provide better utilization of the earth's resources to produce the energy which will be required over the next several decades. It would greatly reduce the risks that are associated with the proliferation of plutonium-containing materials in the plutonium fuel cycle and the biological hazards associated with the production of transplutonium isotopes.

$\underline{\text { Research and Development Required }}$

1. A simple ion-plating and removal process to minimize fuel cycle costs must be designed.

2. Compatibility of the ion-plated layer on thorium and its ability to provide fission product retention must be demonstrated.

3. A reexamination of the use of thorium-uranium alloys in LWRs, heavy water reactors (HWRs), and Liquid Metal Fast Breeder Reactors (LMFBRs) may enable one to implement an extremely simple (hence inexpensive) fuel cycle for the $A B$. 


\section{Ceramics}

The use of $\mathrm{UO}_{2}$ or $\mathrm{ThO}_{2}$ as the fertile material instead of the thorium blanket introduces the following disadvantages:

1. They provide a very low fertile atom density and result in lower fissile atom production.

2. The lower thermal conductivity of the oxides makes heat removal more difficult and produces large temperature gradients in the fertile body.

3. The low thermal conductivity and high elastic moduli produce large thermal stresses in the fertile bodies.

4. Radiation effects in the oxides are complicated due to the steep temperature gradients which result in long-range mass transport and the chemical effects of the various fission product species and even the fertile and fissile species themselves in the oxide [uel bülies. [30]

5. Fission product effects on both the fertile/fuel body and on any cladding used is very complicated, especially due to the liberation of oxygen during the irradiation of the oxide species.[30]

Other fertile species such as thorium carbide, uranium carbide, uranium nitride, or thorium nitride have better fertile atom densities than those of the oxides; however, these atom densities are still only one-half that of the solid metallic thorium. The much higher thernal conductivity of the carbides provides good heat removal and much higher power ratings or fissile atom production rates than those that can be achieved for the oxides. The higher thermal conductivity and lower thermal expansion of the carbides relative to those of the oxides reduce thermal stresses in the fertile bodies, which is a very desirable aspect. Sodium will not extract carbon or nitrogen from stoichiometric or hypostoichiometric uranium carbide, thorium carbide, uranium nitride, or thorium nitride and transport it to the cladding. Radiation effects in these species are less severe than those in the oxides for the same temperature of irradiation and same burnup history. Data on the high-performance irradiation behavior of these materials are now being obtained in the advanced fuels program for the LMFBRs, and that formation may be available for use in the $A B$ concept.

Processing and fabrication of the carbides and nitrides are more difficult and more expensive than those for oxides. Both species must be protected from oxidation and moisture during processing. The carbides and nitrides of thorium or uranium are not as effective as thorium in utilization of our resources, and they are considerably more expensive to process, fabricate, and reprocess.

The fuel reprocessing for the $A B$ would be the same as that used for the reprocessing of fuel from any conventional reactor system and would be included in that program. 


\section{Reactor Fuel Elements}

There are concepts that utilize a standard LWR fuel element containing fertile isotopes only for the blanket.[5,6] These concepts indicate that the fuel element will be irradiated in the $A B$ until a fissile concentration of approximately $4 \%$ is produced in the fertile species, $\mathrm{ThO}_{2}$ or ${ }^{238} \mathrm{UO}_{2}$. The fuel element would then be transferred from the $A B$ to an LWR and used to produce power. Upon depletion of the fissile isotope content, the fuel element would then be returned to the blanket of the $A B$ for rejuvenation of the fissile atom contents. It has been postulated that this could be done several times to avoid the reprocessing operation.

Current materials technology is incapable of successfully conducting such an operation. 'lhe Zircaloy cladding would be severely embrittled, if not cracked, by the copious quantities of hydrogen that would be produced in the cladding by the high energy neutron-induced $(n, p)$ reactions and by the fast neutron-produced radiation damage. Zirconium has a large affinity for hydrogen. This results in the formation of zirconium hydride, $\mathrm{ZrH}_{4}$. The larger volume of the $\mathrm{ZrH}_{4}$, compared with that of zirconium, produces large tensile strains in the clad which result in fracture of the cladding. This is a phenomenon that occurs in existing LWRs at hydrogen concentrations in the few hundred to several hundred appm range.[19] This is equivalent to between 1 and a few days of operation in the $A B$.

In addition, by the time a fisslle atom content of $4 \%$ were produced in the fertile material, a significant number of fissions would have occurred in the fertile-fuel mixture. These fissions would produce fission products that have high thermal-neutron-absorption cross sections. In current LWRs, the fuel is removed when there is insufficient enrichment to overcome the parasitic neutron captures in the coolant $\mathrm{H}_{2} \mathrm{O}$ combined with those that occur due to fission product buildup. Using a fuel element that contains fission products would be inefficient use of the neutrons that are produced in the reactor. The neutrons produced in the reactor are too valuable for power production; they have a certain dollar vallue. To waste these neutrons to capture by fission products is not an acceptable utilization of our resources.

The combination of cladding embrittlement and fission product poisoning of the fuel makes this concept extremely unacceptable. Processing of the fuel will have to be done. The major emphasis should be on making this processing as simple and as incxpensive as possible. An example provided earlier is the simple ion plating of thorium metal.

\section{BLANKET CONTAINER}

The materials technology of the blanket container must meet the following criteria: 
1. resist fracture during operation,

2. be of simple design for easy changeout during shutdown for fuel removal,

3. be chemically compatible with the blanket coolant, and

4. have a low swelling rate to minimize differential stresses.

The radiation environment on the target side of the blanket container is similar to that expected in a fusion reactor and, therefore, to the radiation environment of the target container described earlier in Section B. This side will have large concentrations of helium and hydrogen produced in it, in addition to the high dpa levels. The ability of the blanket container to resist fracture under these conditions must be determined. Fortunately, operating temperatures can be maintained weil below $500^{\circ} \mathrm{C}$, and the container (it of simple design') can be replaced during the removal of fuel and the insertion of additional fertile material.

The blanket container exterior will be exposed to a neutron environment similar to that in an LMFBR. Most of the neutrons will be in the energy range from approximately $10 \mathrm{ReV}$ to approximately MeV; therefore, helium and hydrogen production levels will be considerably less than those on the target side of the container.

Research and Development Required

The research and development required is very similar to that for the target container and should be coordinated so that the experiments conducted will provide the information required for the sucessful operation of both components. Close coordination of materials performance with design options is essential to the operation of the target container and the blanket container for time periods colncident with the shutdown of the $A B$ for fuel removal and fertile material insertion.

\section{E. NEUTRON MUITIPLT.ER}

It may be very desirable in an $A B$ to include a neutron multiplier around the target region. Beryllium or one of its alloys would be the most suitable neutron multiplier for increasing the number of neutrons that is produced in the target. Since only the nuclear properties of the beryllium are utilized, the neutron multiplier can be clad. The physical integrity of beryllium would not matter as long as it did not enter other parts of the system. The cladding could be vented to release the helium pressure. If the helium is vented at a low pressure, the cladding thickness could be minimized for the best neutron economy.

Research and Development Required

The following determinations must be made:

1. the compatibility of the beryllium alloy or compounds with the clad, 
2. the clad thickness required for the desired helium pressure generated, and

3. the lifetime of the clad in the high-energy neutron environment between the target and the blanket.

\section{F. WINDOW BETWEEN ACCELERATOR AND TARGET}

Concepts that are based on targets of oxide particles or reactor fuel elements cooled with $1400-p s i$ helium at high flow rates require the use of a window between the accelerator and the target.[5,6] Irradiation effects produced in such a window will be more like the irradiation effects produced in a fusion reactor structural material than those produced in a fission reactor structural material. For equal particle fluxes, the helium production rate for $1-\mathrm{GeV}$ protons on a typical medium-weight atomic metal will be $10^{4}$ times greater than that for EBR-II energy neutrons which is about $1 / 2 \mathrm{MeV}$ in energy. [31] These rates will be ten times greater than that for fusion energy neutrons. For equal particle fluyes, the hydrogen production rate for $1-\mathrm{GeV}$ protons will be $10^{3}$ times greater than that for EBR-II energy neutrons and approximately three times greater than that for fusion energy neutrons.[29] The atomic displacement rates will be approximately ten times greater than that for EBR-II neutrons.

As described earlier for the target container, at temperatures below approximately 0.3 to $0.4 T_{m}$ (where $T_{m}$ is the melting point in absolute temperature, Kelvin), the helium may not move to induce severe embrittlement of the window alloy; however, the large stress gradients produced in the window by the steep radial temperature gradients that will exist in the window (which are not present in the target wal1) could result in helium migration to grain boundaries, which would result In severe embrittlement and a very short window lifetime. Again, as for the target wall, the mobility of the hydrogen produced in the window alloy will be very important to the ductillty and toughness (i.e., area under the stress-strain curve) of the window. Hydrogen diffusion out of the window would be very desirable and would greatly reduce the ductility decrease that is usually associated with the production of the irradiation damage combined with the presence of hydrogen.

The damage-limiting mechanism for the target window will be the combination of large strains and strain gradients in the window combined with the presence of helium and/or hydrogen in the window material. By selecting a low atomic number alloy where the effects of hydrogen and helium may be minimized such as $\mathrm{V}-20 \mathrm{wt} \% \mathrm{~T} i$, it may be possible to achieve window lifetimes that are satisfactory for the economic and reliable production of fissile material in the accelerator breeder.

There is research currently under way to study irradiation effects in windows at the Los Alamos Meson Physics Facility, LAMPF, under a DOE Divisiun of Physical Reserach Program. This is an ideal facility for this work. 
The LAMPF operating at $50 \mu \mathrm{A}$ produces $1.56 \times 10^{15}$ protons $/ \mathrm{cm}^{2} \mathrm{~s}$ on a target sample; this is very close to the $1.64 \times 10^{15}$ protons $/ \mathrm{cm}^{2} \mathrm{~s}$ of the Brookhaven National Laboratory design. [5] At higher LAMPF beam currents, accelerated testing of window materials for the $A B$ should be possible. Calculations have been initiated on the effect of $800-\mathrm{MeV}$ protons on helium, hydrogen, and dpa production for $\mathrm{Ti}, \mathrm{V}$, and $\mathrm{V}-20 \mathrm{wt} \% \mathrm{Ti}$. Sample materials are being prepared of $\mathrm{V}, \mathrm{Ti}$, and $\mathrm{V}-\mathrm{Ti}$ alloys for irradiation in the new PIP. Information obtained from this research should provide valuable irradiation effects information for the $A B$ concept that requires the presence of a window between the accelerator and the target.

\section{Research and Development Required}

The following determinations must be made:

1. Calculations on the dpa, He, and $\mathrm{H}$ in $\mathrm{V}, \mathrm{Ti}$, and $\mathrm{V}-20$ wt $\% \mathrm{Ti}$ and other candidate materials for $1-\mathrm{GeV}$ protons at $300 \mathrm{~mA}$;

2. irradiation of these materials at LAMPF under the conditions most relevant to the $A B$ that can be achieved at LAMPF;

3. calculations on the strain and strain gradients produced in the window as a function of window diameter and thickness, as a function of accelerator vacuum and helium pressure on the two sides of the window, and as a function of beam power and beam power losses in the window; and

4. scale the LAMPF target facility up from its current 1 by 2 by $1 / 4-\mathrm{mm}-$ thick sample size to sizes more relevant to the $A B$ by uti,1,i.ing the higher beam currents that have been achieved at LAMPF. Maximum beam currents to data have been approximately $300 \mu \mathrm{A}$, and the eventual goal is $1 \mathrm{~mA}$.

Determination and recommendation of the best research and development program would have to be developed during the initial phases of funding of the study to evaluate the potential of the $A B$. The window will be by orders of magnitude the most difficult and expensive portion of the materials technology for the $A B$ if it is decided that the concepts requiring a window merit further evaluation.

The author is extremely grateful to the following persons for their respective contributions to this paper: J. H. DeVan and J. R. Weeks for helpful discussions on liquid metal compatibility; M. J. Kania for assistance in evaluating fuel particle performance limits; W. A. Cughlin, K. Furrell, J. O. Stiegler, and F. W. Wiffen for their review of this report and their many helpful suggestions.

\section{REFERENCES}

1. G. A. Bartholomew and P. R. Tunnicliffe (eds.), "The AECL Study for an Intense Neutron Generator," Technical Details, AECL-2600 (1966).

2. R. R. Fullwod et al., Neutron Production by Medium Energy Protons on Heavy Metal Targets, LA-4789 (1972). 
3. J. C. Vigil, Proposal for a Feasibility Study of Electronuclear

Fuel Production, Los Alamos Scientific Laboratory (September 1976).

4. C. M. Von Atta et al., The Electronuclear Conversion of Fertile to Fissile Material, UCRL-52144 (October 1976).

5. M. Steinberg et al., Linear Accelerator Breeder, BNL-50592 (November 1976).

6. F. R. Mynatt et. al., Preliminary Report on the Promise of Accelerator Breeding and Converter Reactor Symbiosis (ABACS) as an Alternative Energy System, ORNL/TM-5750 (1977).

7. J. H. DeVan, ORNL, private communication, December 1976.

8. J. R. Weeks, BNL, private communication, February 1977: and Nucl. Eng. Des. 15: 363 (1972).

9. J. A. Horak, J. A. Reuscher, and D. J. Sasmor, Symposium on Materials Performance in Operating Nuclear Systems, CONF-730801, Nucl. Met. 19: 203 (1973).

10. B. Fleischer to D. B. Lloyd, ORNL, private communication, Dec. 22, 1969.

11. D. M. Mattox, "Recent Advances in Ion Plating," p. 443 in Proceedings of the Sixth International Vacuum Congress, 1974.

12. D. M. Mattox, Ion Plating - Concepts and Applications, SAND 76-5459A (1976).

13. J. A. Reuscher, Sandia Laboratories, private communication, February 1977.

14. T. 0. Ziebold, F. G. Foote, and R. F. Smith, "Materials and Metallurgy," Chap. 12, and D. H. Gurinsky and S. Isserow, "Nuclear Fuels," Chap. 13 in The Technology of Nuclear Reactor Safety, Vol. 2 Reactor Materials and Engineering, ed. by T. J. Thompson and J. G. Beckerley, MIT Press, Cambridge, Mass., 1973.

15. J. F. Smith, O. N. Carlson, D. T. Peterson, and T. E. Scott, THORIUM: Preparation and Properties, IOWA State University Press, Ames, 1975.

16. P. R. Kasten et al., Assessment of the Thomium Fuel Cycle in Power Reactors, ORNL/TM-5565 (January 1977).

17. 0. M. Stansfield, HTGR Fuel Design and Performance, GA-A-13072 (1974).

18. T. B. Lindemer and H. J. deNordwal1, An Analysis of Chemical Failure of Coated $\mathrm{UO}_{2}$ and other Oxide Fuels in the High Temperature Gas-Cooled Reactor, ORIL-4926 (1974).

19. W. P. Chernock, "Zirconium in Water Reactors," in Proceedings of the American Institute of Chemical Engineers Materials Conference, Philadelphia, Pa., Apr. 4, 1968.

20. H. Wiedersich, J. J. Burton, and J. L. Katz, J. NucZ. Mater. 51: 287 (1974).

21. K. Farrel1, A. Wolfenden, and R. T. King, "The Effects of Irradiation Temperature and Preinjected Gases on Voids in Aluminum," Radiat. Eff. 8: 107 (1971).

22. K. Farrell and J. T. Houston, "Combined Effects of Displacement Damage and High Gas Content in Aluminum," p. 209 in Radiation Effects and Tritium Technology for Fusion Reactors, Vol. II, CONF-750989, 1976.

23. R. L. Carlé, G. W. Hardigg, and K. Traube, "The Liquid-Metal Fast Breeder Reactors," Trans. Am. Nucl Soc. 24: 15 (November 1976).

24. F. W. Wiffen, The Effects of CTR Irradiation on the Mechanical Properties of Structural Materials, ORNL/TM-5624 (November 1976).

25. P. J. Maziasx, ORNL, private communication, January 1977. 
26. J. A. Horak and F. W. Wiffen, to be published in Nuclear Technology.

27. J. H. Kittel, J. A. Horak, W. F. Murphy, and S. H. Paine, Effects of Irradiation on Thorium and Thorium-Uranium AlZoys, ANL-5674 (1963).

28. R. D. Leggett and R. S. Kemper (eds.), Status of Thorium Fuel Technology, BNWL-861 (1968).

29. S. Peterson, R. E. Adams, and D. A. Douglas, Jr., Properties of Thorium, Its AlZoys, and Its Compounds, ORNL-TM-1144 (June 1965).

30. D. R. Ollander, Fundamental Aspects of Nuclear Reactor. Fuel Elements, TID-26711, USERDA (1976).

31. C. A. Coulter, D. M. Parkin, and W. V. Green, Calculation of Radiation Damage Effects of 800 MeV Protons in a Thin Coppen Tanget, LA-6294-MS (April 1976). 
ORNL/TM-6156

Distribution

Category UC-25

INTERNAL DISTRIBUTION

1-2. Central Research Library

58. C. J. McHargue

3. Document Reference Section

59. H. Postma

4-6. Laboratory Records Department

60. M. W. Rosenthal

7. Laboratory Records, ORNL RC

61. M. J. Saltmarsh

8. ORNL Patent office

62. D. L. Selby

9. S. E. Beall

63. R. L. Simard

10. F. K. Bruce

64. I. Spiewak

11. J. E. Cunningham

65. P. H. Stilson

12. R. G. Donnelly

66. J. 0. Stiegler

13. K. Farre11

14. W. O. Harms

15-17. M. R. Hill

18-52. J. A. Horak

67. D. B. Trauger

68. J. R. Weir, Jr.

69. M. K. Wilkinson

53. P. R. Kasten

70. A. Zucker

54. C. C. Koch

71. R. W. Balluffi (consultant)

55. A. L. Lotts

72. P. M. Brister (consultant)

56. F. C. Maienschein

73. W. R. Hibbard, Jr. (consultant)

57. J. A. Martin

74. N. E. Promisel (consultant)

\section{EXTERNAL DISTRIBUTION}

75. AECL, CHALK RIVER NUCLEAR LABS, Chalk River, Ontario KOJ1JO, Canada. P. R. Tunnicliffe

76. AECL, WHITESHELL NUCLEAR RESEARCH ESTABLISHMENT, Pinawa Manitoba, Canada, ROElLO

J. Boulton

77. ARGONNE NATIONAL LABORATORY, 9700 South Cass Ave., Argonne, IL 60439

J. H. Kittel

78. ARGONNE NATIONAL LABORATORY, P.O. Box 2528, Idaho Fal1s, ID 83401

C. M. Walter

79-82. BROOKHAVEN NATIONAL LABORATORY, Upton, LI, NY 11973

H.J.C. Kouts

J. R. Powel1

M. Steinberg

G. H. Vineyard

83. CENTRAL ELECTRICITY GENERATING BOARD, Berkeley, Gloucestẹtershire, $\mathrm{U} . \mathrm{K}$.

J. Harris 
EXTERNAL DISTRIBUTION

84. COMBUStION ENGINEERING, 1000 Prospect Hill Road, Windsor, CT 06095

G. Chalder

85. GENERAL ATOMIC COMPANY, P.0. Box 81608, San Diego, CA 92138

M. T. Simnad

86. HANFORD ENGINEERING DEVELOPMENT LABORATORY, P.0. BOX 1970, Richland, WA 99352

R. U. Leggett

87-gU. LOS ALAMOS SCIENTT̃IFİC LABORATORY, P.0. Box '1663, Los Alamos, NM 87545
H. M. Agnew
W. V. Green
L. Rosen
R. F. Taschek

91-95. DOE DIVISION OF CONTROLLED THERMONUCLEAR RESEARCH, Washington, DC 20545

S. L. Bogart

J. F. Clarke

T. C. Reuther

J. M. Williams

K. M. Zwilsky

96. DOE DIVISION OF PHYSICAL RESEARCH, Washington, DC 20545

D. K. Steveno

97. DOE. NUCLEAR RESEARCH APPLICATION, Washington, DC 20545

S. Strauch

98-99. DOE RESEARCH DEVELOPMENT AND DEMONSTRATION, Washington, DC 20545

J. W. Bennett

W. M. Hartman

100-101. DOE OAK RIDGE OPERATIONS OFFICE, P. . Box E, Oak Ridge, TN 37830

Diresto:

Research and Technical Support Division

102-328. DOE TECHNICAL INFORMATION CENTER, Office of Information Services, P.O. Box 62, Oak Ridge, TN 37830

Given distribution as shown in TID-4500 under UC-25 Materials. 